\title{
Biochemical Changes in Skin Composition in Spinal Cord Injury: A Possible Contribution to Decubitus Ulcers
}

\author{
G. P. Rodriguez, MS, J. Claus-Walker, PhD \\ Baylor College of Medicine and The Institute for Rehabilitation and Research, \\ Houston, Texas, USA.
}

\begin{abstract}
Summary
Patients with spinal cord injury (SCI) have an increased susceptibility to ulcers of the skin due to pressure. Immediately after the injury, SCI patients have a greatly increased degradation of collagen from both bone and skin. Loss of collagen from the skin could account for a reduction of the skin's ability to resist mechanical insults. This paper describes the results of an investigation into the role of collagen metabolism in the etiology of pressure ulcers. Skin biopsies have been obtained from healthy non-paralysed volunteers, and from insensitive and sensitive skin in SCI patients. The amino acid content of the insensitive skin was considerably lower than in sensitive skin. The activity of the enzyme lysyl hydroxylase was also lower in the insensitive skin. Lysyl hydroxylase activity in the sensitive skin was similar to enzyme activity in control skin biopsies of the same body area.
\end{abstract}

Key words: Cutaneous pressure ulcers; Spinal cord injury; Collagen metabolism; Lysyl hydroxylase.

One of the complications of spinal cord injury (SCI) is an increased susceptibility to skin pressure ulcers, which is costly in money and in time in hospital (Anderson, 1979; Stover, 1986; Young, 1981). An understanding of all the factors involved in this increased sensitivity to pressure is essential before the condition can be prevented, and perhaps eradicated.

Injury to the upper part of the spinal cord produces a large and immediate increase in the degradation of collagen, not only of bone but also of skin (ClausWalker et al., 1977). This loss is detected by a large increase in the urinary excretion of collagen metabolites such as hydroxyproline (Hyp), hydroxylysine $(\mathrm{Hyl})$, and of glucosylgalactosyl hydroxylysine derived especially from the skin (Claus-Walker et al., 1977; Claus-Walker, 1980; Claus-Walker and Halstead, 1981, 1982; Rodriguez et al., 1984).

The loss of bone collagen is implicated in the development of osteoporosis of the paralyzed skeleton in SCI patients (Chantraine, 1978). By analogy, the loss 
Table I Description of subjects

\begin{tabular}{|c|c|c|c|c|c|c|}
\hline & \multirow[b]{2}{*}{$\mathrm{n}$} & \multicolumn{2}{|c|}{ Sex } & \multirow{2}{*}{$\begin{array}{c}\text { Age } \\
\text { years } \\
(\text { mean } \pm \text { SEM })\end{array}$} & \multicolumn{2}{|c|}{ Race } \\
\hline & & Male & Female & & Black & White \\
\hline Controls & 10 & 8 & 2 & $29 \pm 2.2$ & 0 & 10 \\
\hline SCI & 7 & 5 & 2 & $33 \pm 4.4$ & 2 & 5 \\
\hline
\end{tabular}

of skin collagen, could be implicated in a reduction of the skin's ability to resist mechanical insults. Thus, a loss of skin collagen could be a factor leading to the increased susceptibility to pressure ulcers among the SCI population (Hunter and Rajan, 1971 [see Claus-Walker et al., 1977]).

The object of this study is to discover if there are differences in the amino acid composition and in the activity of one of the enzymes of collagen biosynthesis in the insensitive ${ }^{\star}$ skin when compared to sensitive $\dagger$ skin from SCI patients or to skin from ambulatory controls.

\section{Materials and methods}

Subjects were patients admitted to The Institute for Rehabilitation and Research (TIRR) for surgical repair of pressure ulcers. Controls were healthy volunteers. After obtaining informed consent, each patient allowed us to take two $4 \mathrm{~mm}$ punch biopsies: one from the sensitive skin above the level of the injury (skin overlying the posterior deltoid muscle) and another from the insensitive skin used to repair the ulcer. The biopsy below the level of injury was surplus skin from the surgical repair flap obtained from the superior buttock or the lateral thigh. Biopsies were kept frozen under liquid nitrogen until they were assayed.

Subject characteristics are described in Table I. There were 10 controls and 7 patients. Sex and age distribution was similar in the two groups. It was not possible to carry out all of the studies in each biopsy because of the small size of the punch biopsies.

\section{Amino acid assay}

Biopsies were weighed, homogenised and lyophilised. The powder was defatted with acetone. Portions of the powder were hydrolysed in $6 \mathrm{~N} \mathrm{HCl}$, evaporated to dryness, reconstituted in $\mathrm{pH} 2.2$ lithium citrate buffer and sujected to chromatography in a Beckman 119CL amino acid analyser. Concentrations of proline (Pro), lysine (Lys), hydroxyproline ( $\mathrm{Hyp}$ ) and hydroxylysine ( $\mathrm{Hyl})$ are reported as nanomoles of amino acid per milligram of dried defatted skin. The ratios $\mathrm{Hyp} /$ Pro and $\mathrm{Hyl} / \mathrm{Lys}$ are used to assess the rate of hydroxylation of Pro and Lys respectively.

\section{Lysyl hydroxylase activity}

Lysyl hydroxylase assays were carried out on skin homogenates. Either the entire skin biopsy or a portion of the flap skin was homogenised in enough

* Innervated by fibres from the part of the spinal cord separated from the brain.

$\dagger$ Innervated by fibres from the part of the spinal cord attached to the brain. 
Table II Amino acid content * of skin biopsies in SCI patients

\begin{tabular}{|c|c|c|c|c|c|c|c|}
\hline Biopsy site & $\mathrm{n}$ & Hyp & Pro & $\frac{\text { Hyp }}{\text { Pro }}$ & Hyl & Lys & $\frac{\mathrm{Hyl}}{\mathrm{Lys}}$ \\
\hline Sensitive & 3 & $\begin{array}{c}1099 \pm \\
118\end{array}$ & $\begin{array}{c}1665 \pm \\
184\end{array}$ & $\begin{array}{c}0.66 \pm \\
0.02\end{array}$ & $\begin{array}{c}71 \pm \\
10 .\end{array}$ & $\begin{array}{c}307 \pm \\
65\end{array}$ & $\begin{array}{c}0.24 \pm \\
0.02\end{array}$ \\
\hline Insensitive & 7 & $\begin{array}{c}558 \pm \\
75\end{array}$ & $\begin{array}{c}891 \pm \\
90\end{array}$ & $\begin{array}{c}0.61 \pm \\
0.03\end{array}$ & $\begin{array}{c}44 \pm \\
5.3\end{array}$ & $\begin{array}{c}176 \pm \\
28\end{array}$ & $\begin{array}{c}0.26 \pm \\
0.02\end{array}$ \\
\hline Difference & & $541^{\mathrm{a}}$ & $774^{\mathrm{a}}$ & 0.05 & $27^{\mathrm{b}}$ & 131 & $0.02^{\mathrm{b}}$ \\
\hline
\end{tabular}

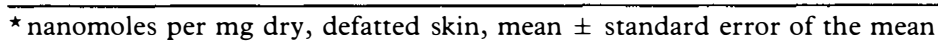

$\mathrm{a}=\mathrm{p}<0.01$

$\mathrm{b}=\mathrm{p}<0.05$

Table III Amino acid content ${ }^{\star}$ of skin biopsies on 3 individual patients

\begin{tabular}{|c|c|c|c|c|c|c|c|}
\hline \multirow[b]{2}{*}{$\mathrm{Pt}$} & \multirow{2}{*}{$\begin{array}{c}\text { Biopsy } \\
\text { Site }\end{array}$} & \multirow[b]{2}{*}{ Hyp } & \multicolumn{3}{|c|}{ Hyp } & \multirow[b]{2}{*}{ Lys } & \multirow{2}{*}{$\frac{\text { Hyl }}{\text { Lys }}$} \\
\hline & & & Pro & $\overline{\text { Pro }}$ & Hyl & & \\
\hline \multirow{2}{*}{ MC } & Sensitive & 1126 & 1612 & 0.70 & 80 & 334 & 0.24 \\
\hline & Insensitive & 294 & 605 & 0.49 & 58 & 283 & 0.20 \\
\hline \multirow{2}{*}{ CF } & Sensitive & 1290 & 2007 & 0.64 & 83 & 404 & 0.21 \\
\hline & Insensitive & 354 & 664 & 0.53 & 63 & 281 & 0.22 \\
\hline \multirow{2}{*}{$\mathrm{TM}$} & Sensitive & 882 & 1377 & 0.64 & 50 & 182 & 0.27 \\
\hline & Insensitive & 565 & 895 & 0.63 & 33 & 127 & 0.26 \\
\hline
\end{tabular}

^ nanomoles of amino acid per mg dry defatted skin

extraction buffer to have between 5 and 40 milligrams of wet skin per 200 ul of homogenate. The extraction procedure is that described by TurpeenniemiHujanen et al. (1980). Tritiated lysine procollagen substrate was prepared according to the method of Miller (1972), using decapitated 14 day chick embryos instead of carrageenan induced guinea pig granuloma tissue. Enzyme activity was assayed by the method of Miller (1972) as modified by Peterkofsky and DiBlasio (1975). In this method, activity is related to the radioactivity of released tritiated water measured in a scintillation counter (Packard Tri Carb, model 4530), expressed as counts per minute per milligram of skin or per milligram of protein. The scintillation cocktail used was Amersham's ACS. Protein was assayed by the Bradford method (Bradford, 1976).

\section{Data analysis}

Data on the amino acid content of the skin were analysed using analysis of variance and the Neuman-Keuls test for multiple comparisons. The NeumanKeuls test determines which of the groups in the analysis of variance are responsible for the differential results. Data on the enzyme activity were analysed using $t$-test for independent samples. These procedures are contained in a computer program, PC Statistician, Human Systems Dynamics, Northridge, CA.

\section{Results}

Results from the amino acid assay on patient biopsies, expressed as nanomoles of amino acid per milligram of dry defatted skin, are presented in Table II. 


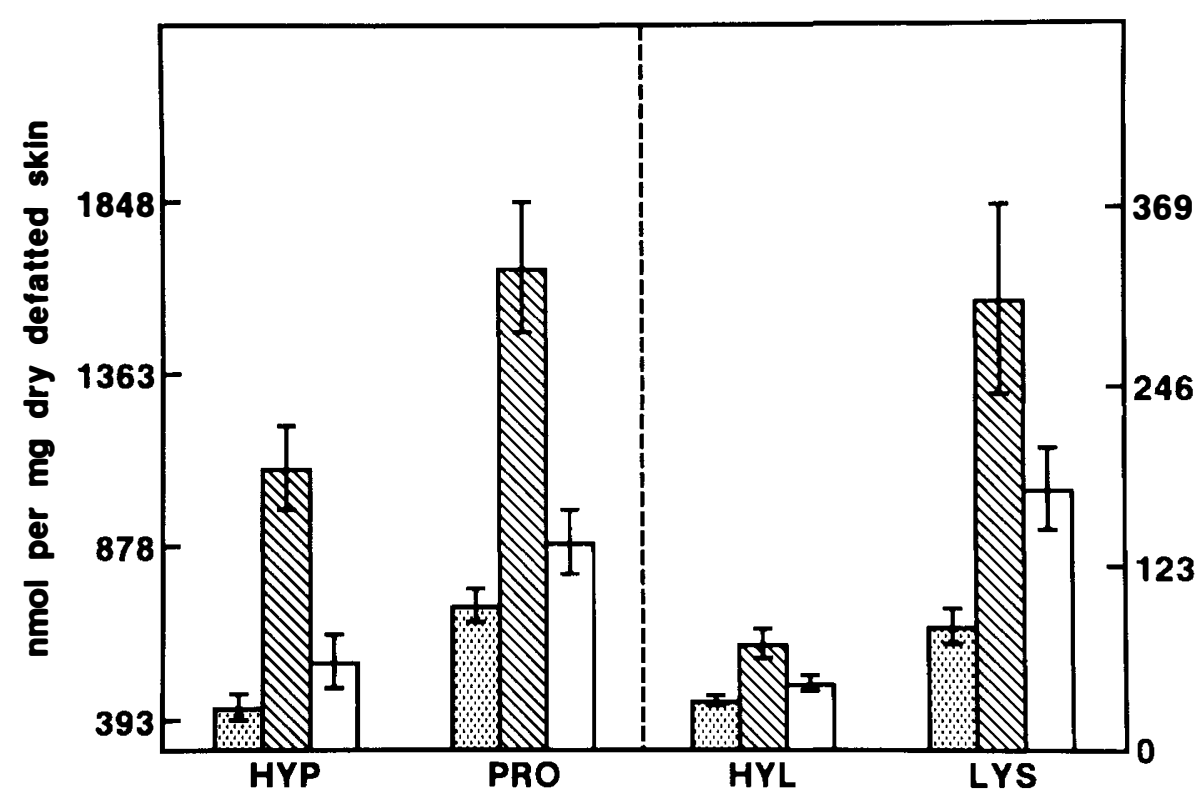

Figure 1 Amino acid composition of skin biopsies in nanomoles per mg dry defatted skin. Left side $\mathrm{y}$-axis values apply to Hyp and Pro; right side to $\mathrm{Hyl}$ and Lys. Control skin ( $\square$ ) $\mathrm{n}=2$; sensitive skin $(\mathbb{\mathbb { N }}) \mathrm{n}=3$; insensitive skin $(\square) \mathrm{n}=7$. Vertical bars show standard error.

There is a decrease in amino acid content in insensitive skin compared to sensitive skin. Differences (d) are: Hyp, - 541; Pro, - 774; Hyl, - 27; Lys, -131 $\mathrm{nmol} / \mathrm{mg}$ dry defatted skin. The decreases are statistically significant for Hyp, Pro, and Hyl ( $\mathrm{p}<0.05)$.

Table III shows the results on three patients (CM, TM and FT) on which we were able to do amino acid assays on biopsies from both sensitive and insensitive skin using each patient as his own control. In all three patients, the amino acid content of the sensitive skin was higher than the content of the insensitive skin. Expressed as nmol/mg dry defatted skin, the results are: Patient CM: Hyp 1126 vs 294, Pro 1612 vs 605, Hyl 80 vs 58, Lys 334 vs 283; Patient FC; Hyp 1290 vs 354, Pro 2007 vs 664, Hyl 83 vs 63, Lys 404 vs 281; Patient TM: Hyp 882 vs 565, Pro 1377 vs 895, Hyl 50 vs 33, Lys 182 vs 127.

In Figure 1, results of assays in two control skins are shown alongside the patient results. The control values, Hyp: 430, Pro: 712, Hyl: 32, Lys: 83 $\mathrm{nmol} / \mathrm{mg}$ dry defatted skin, are in the same range as in the insensitive skin.

Figure 2 shows the calculated ratios Hyp/Pro and Hyl/Lys. The ratio Hyp/Pro is similar in all three groups: control 0.61 , sensitive 0.66 , insensitive 0.61 . In contrast, the ratio $\mathrm{Hyl} /$ Lys is significantly higher $(\mathrm{p}<0.05)$ in controls than in patients: control 0.41 , sensitive 0.24 , insensitive 0.26 .

Figure 3 shows the results of the lysyl hydroxylase assays. The enzyme activity in insensitive skin is much lower than in control and sensitive skin. Expressed as CPM per milligram of skin, differences were: from control 137, p $<0.02$; from sensitive skin $d=143, p<0.057$. Expressed as CPM per milligram of 


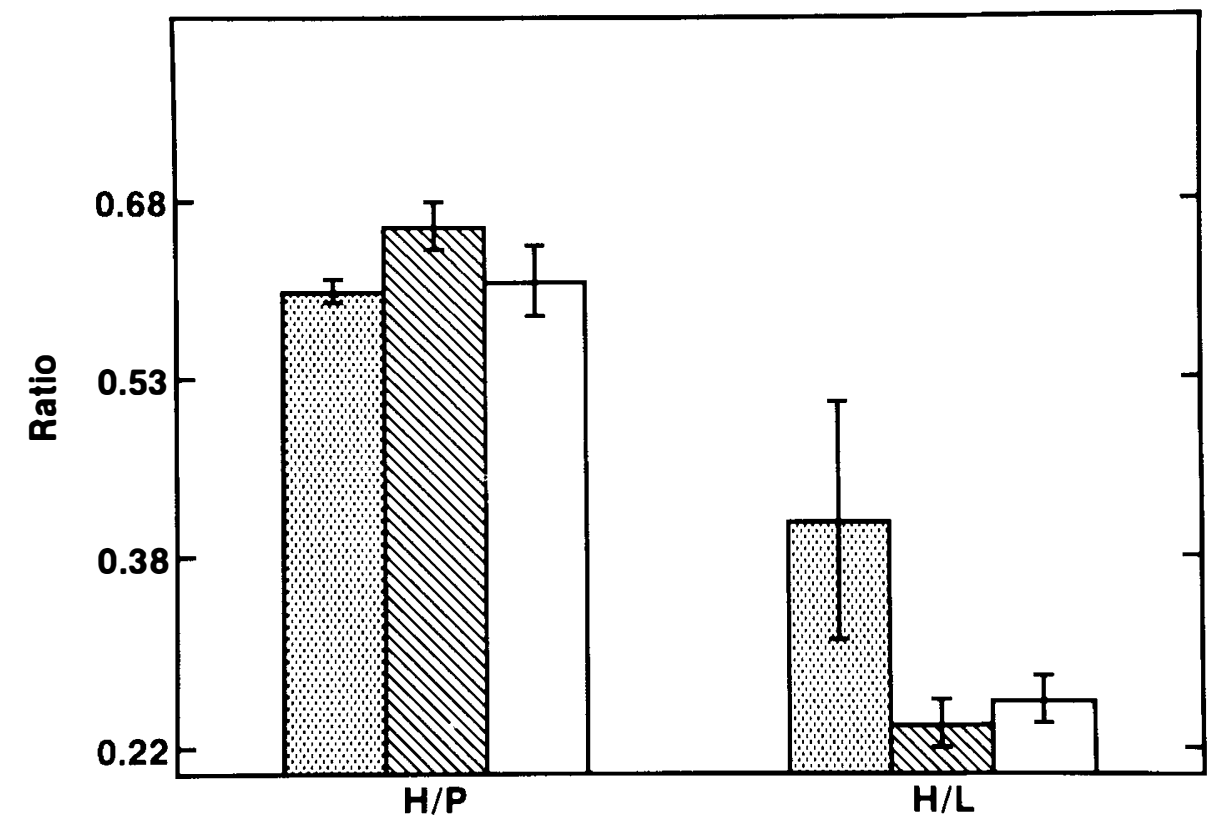

Figure 2 Hydroxylation rate expressed as the ratios $\mathrm{Hyp} / \operatorname{Pro}(\mathrm{H} / \mathrm{P})$ and $\mathrm{Hyl} / \mathrm{Lys}(\mathrm{H} / \mathrm{L})$ on the same biopsies in Figure 1. Identification same as Figure 1.

protein, differences were: from control $\mathrm{d}=14035, \mathrm{p}<0.03$; from sensitive $\mathrm{d}=$ $13055, \mathrm{p}<0.02$.

\section{Discussion}

The difference in the amino acid content of the sensitive skin compared to the insensitive skin is evident whether group means or individual patient's results are compared. The insensitive skin has a greatly decreased amino acid content per unit weight. This could be one of the factors responsible for the decreased ability of the insensitive skin to resist mechanical insults, since it is the collagen in the skin that provides its great tensile strength (Prockop, 1979). The waterbridges that Hyp forms with other amino acids in the collagen helix are the main factor establishing the mechanical and thermal stability of the collagen fibrils (Traub, 1974; Nemethy, 1986). The hydroxylation rate of Pro, expressed as the ratio $\mathrm{Hyp} /$ Pro, is lower in the skin below the level of injury. This factor, in addition to the lower total content of all four amino acids, would contribute to the weakening of the skin matrix.

Interpretation of the difference in amino acid content between control skin and sensitive and insensitive skin in SCI has to be more cautious, because we were only able to do two amino acid assays in the controls. In addition, SCI affects total body composition. The extracellular water compartment is expanded and intracellular water is decreased (Cardus, 1984; Chantraine, 1976). The glycosaminoglycans, which form part of the ground substance surrounding the collagen molecule, are probably decreased, since increased urinary glycosaminoglycan excretion parallels that of hydroxyproline in its duration but 


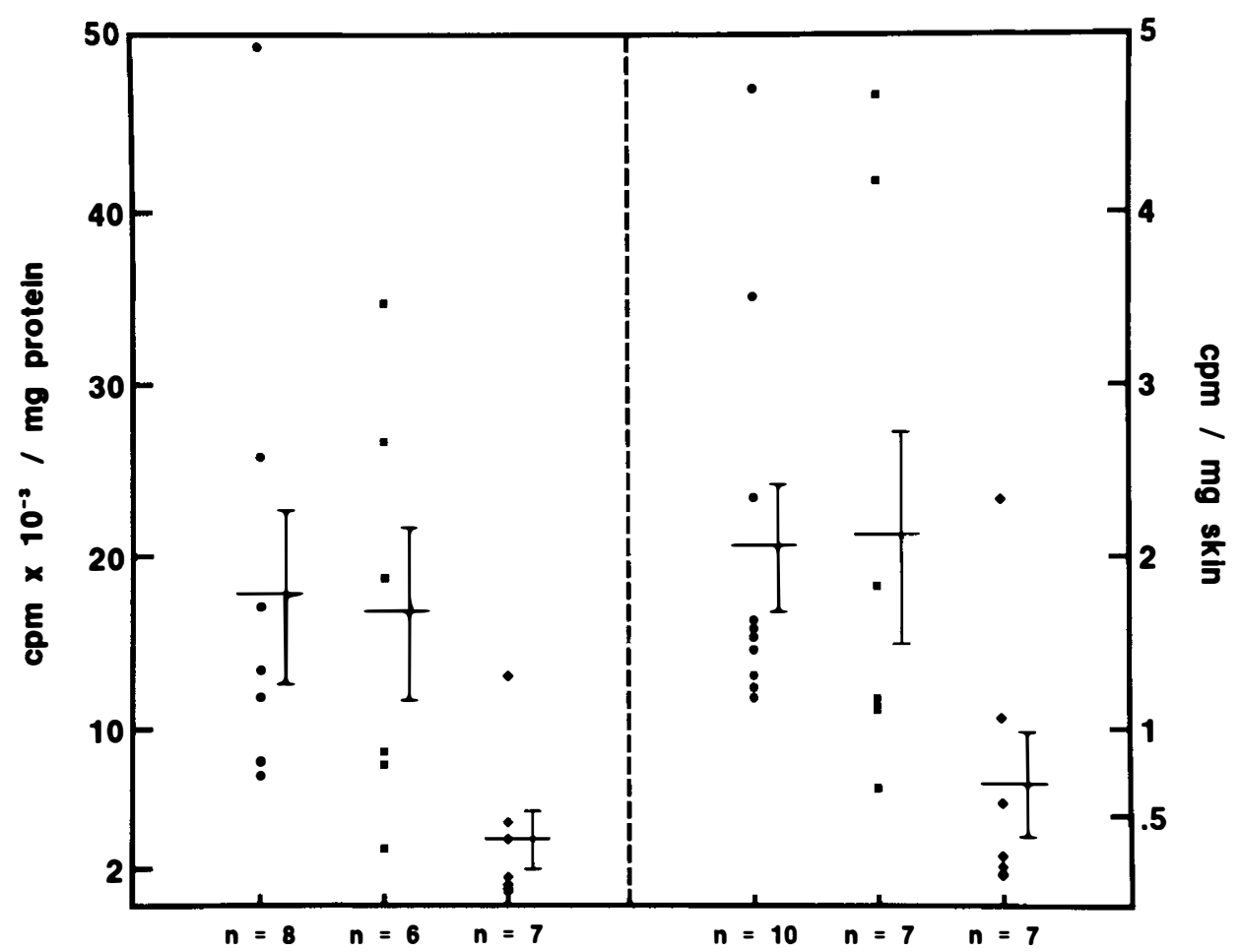

Figure 3 Lysyl hydroxylase activity in skin biopsies expressed as counts per minute per mg protein (left) and per $\mathrm{mg}$ wet skin (right). Control $=\boldsymbol{0}$, sensitive $=\mathbf{\square}$, insensitive $=$ Horizontal lines indicate means. Vertical bars show standard error.

exceeds it in magnitude (Pilonchery, 1983; Singh, 1977). Changes in fat and non-collagenous protein content have been noted (Greenway, 1970). In short, the residue of lyophilised and defatted skin may contain different proportions of collagen and non-collagen material in controls and patients. Therefore, comparisons of amino acid content per unit weight of skin may be valid when comparing biopsies from the same patient or similar patients, but may not be as valid when comparing biopsies from patients and healthy subjects. Theoretically, we should compare amino acid content per unit volume of skin. Practically, this is difficult because of the minute quantity of skin obtained by punch biopsy.

In contrast, the assay for lysyl hydroxylase approximates measurements on equal volumes of skin since it is done on skin homogenates containing comparable amounts of wet skin. The results present a more logical picture of the biosynthetic activity of the skin collagen. The hydroxylation of Lys is an important first step in collagen crosslink formation. Decreased formation of $\mathrm{Hyl}$ will decrease crosslink formation and will produce a structurally weaker collagen and skin (Prockop, 1979). Lysyl hydroxylase activity is lower in the biopsies of insensitive skin than in sensitive skin. The enzyme activity of the insensitive skin is reduced in proportion to the decrease in amino acid content so that the rate of hydroxylation of Lys is the same in insensitive or sensitive skin but the 
absoulte content of $\mathrm{Hyl}$ is much less in insensitive skin. It will be of interest to find out if prolyl hydroxylase activity is affected similarly by SCI since the rate of hydroxylation of Pro is also lower in insensitive skin.

The incidence of skin pressure ulcers in the SCI population is not evenly distributed. Some patients tend to get pressure ulcers repeatedly, and some do not. Injuries to the same spinal segment can be accompanied by variable neuronal damage affecting differently adrenergic function, capillary circulation, cellular nutrition and tissue oxygenation. The SCI patient's autonomic nervous system is impaired, especially in those injured above the T6 level (Lindan, 1980; Mathias, 1975). There are indications of a deficit in the density of adrenergic receptors as a function of time since injury (Rodriguez, 1986) which would have an effect on cardiovascular responses. SCI patients have a reduced blood supply below the level of injury which might reduce the delivery of nutrients to the tissues and decrease the availability of enzyme cofactors such as ascorbic acid and molecular oxygen (Hunt, 1978). This localised malnutrition would affect the biosynthesis of the collagen molecule leading to the formation of defective collagen fibrils. The relationship between level and completeness of injury, degree of spasticity, movement and distorting forces on the skin, collagen abnormalities, and/or nutritional status should be examined. We need to obtain more information on the skin of healthy controls, and, finally, further research is needed to determine if in patients who do not have ulcers, collagen biosynthesis has been only minimally affected.

\section{Acknowledgement}

This work was supported in part by the Mary E. Switzer Research Fellowship awarded to Ms Rodriguez by The National Institute of Handicapped Research of the United States Department of Education and by grant No. G008300044 from the Department of Education.

We wish to thank Samuel Stal, MD for his encouragement and advice and Steven M. Hamilton, MD for his help in obtaining the specimens.

\section{References}

ANDERSON P, ARDLEy M 1979 Psychosocial factors associated with pressure sores. Archives of Physical and Medical Rehabilitation 60:341-346.

BRADFORD MM 1976 A rapid and sensitive method for the quantitation of microgram quantities of protein utilising the principle of protein-dye binding. Analytical Biochemstry 72:248-254.

CARDUS D, MCTAGGaRT WG 1984 Total body water and its distribution in men with spinal cord injury. Archives of Physical and Medical Rehabilitation 65:509-512.

Chantraine A, Delnaide PA 1976 Hydroelectrolytic determination in paraplegics (Total body water; exchangeable sodium and total body potassium). Paraplegia 14:138-145.

Chantraine A 1978 Actual concept of osteoporosis in paraplegia. Paraplegia 16:51-58.

Claus-WALKER J et al. 1977 The urinary excretion of collagen degradation products by quadriplegic patients and during weightlessness. Fournal of Bone and foint Surgery 59(A):209212.

Claus-WalKeR J 1980 Clinical implications of the disturbance in calcium and collagen metabolism in quadriplegia. International fournal of Rehabilitation Research 3:(4)540-541.

Claus-Walker J, Halstead LS 1981 Metabolic and endocrine changes in spinal cord injury. Part I. The nervous system before and after transection of the spinal cord. Archives of Physical and Medical Rehabilitation 62:595-601.

Claus-Walker J, Halstead LS 1982 Metabolic and endocrine changes in spinal cord injury. Part II. Section 1. Consequences of partial decentralisation of the automatic nervous system. Archives of Physical and Medical Rehabilitation 63(11):569-575. 
Claus-Walker J, Halstead LS 1982 Metabolic and endocrine changes in spinal cord injury. Part II, Section 2. Partial decentralisation of the autonomic nervous system, continued. Archives of Physical Medical Rehabilitation 63(11):576-580.

Claus-Walker J, Halstead LS 1982 Metabolic and endocrine changes in spinal cord injury. Part III. Less quanta of sensory input plus bedrest and illness. Archives of Physical and Medical Rehabilitation 63(12):628-631.

Claus-Walker J, Halstead LS 1982 Metabolic and endocrine changes in spinal cord injury. Part IV. Compounded neurologic dysfunctions. Archives of Physical and Medical Rehabilitation 63(12):632-638.

GREENWAY RM et al. 1970 Long-term changes in gross body composition of paraplegic and quadriplegic patients. Paraplegia 7:301-318.

HUNT RK et al. 1978 Anaerobic metabolism and wound healing: An hypothesis for the initiation and cessation of collagen synthesis in wounds. American fournal of Surgery 135:328.

HUNTER T, RAJAN KT 1971 The role of ascorbic acid in the pathogenesis and treatment of pressure sores. Paraplegia 8:211.

LINDAN R et al. 1980 Incidence and clinical features of autonomic dysreflexia in patients with spinal cord injury. Paraplegia 18:285-292.

MATHIAS CJ et al. 1975 Plasma catecholamines, plasma renin activity and plasma aldosterone in tetraplegic man, horizontal and tilted. Clinical Science of Molecular Medicine 49:291-299.

MILler RL 1972 Rapid assay for lysyl-protocollagen hydroxylase activity. Analytical Biochemistry 45:202-210.

NeMETHY G, SCHERAGA HA 1986 Stabilization of collagen fibrils by hydroxyproline. Biochemistry 25:3184-3188.

Peterkofsky B, DiBlasio R 1975 Modification of the tritium release assays for prolyl and lysyl hydroxylases using Dowex-50 columns. Analytical Biochemistry 66:279-286.

PILONCHERY G et al. 1983 Urinary elimination of glycosaminoglycans during the immobilisation osteoporosis of spinal cord injury patients. Clinical Orthopoedics 174:230-235.

PRockop DJ et al. 1979 The biosynthesis of collagen and its disorders. New England fournal of Medicine 301:13-23.

RODRIGUez GP, Claus-Walker J 1984 Measurement of hydroxylysine glycosides in urine and its application to spinal cord injury. Fournal of Chromatography 308:65-73.

RODRIGUEZ GP et al. 1986 Adrenergic receptors in insensitive skin of spinal cord injury patients. Archives of Physical and Medical Rehabilitation 67:177-180.

SiNGH J et al. 1977 Urinary excretion of glycosaminoglycans in quadriplegia. Proceedings of the Society of Experimental Biological Medicine 156:488-490.

Stover SL, FINE PR (eds) 1986 Spinal Cord Injury: The facts and figures. The University of Alabama at Birmingham, Alabama.

TRAUB W 1974 Some stereochemical implications of the molecular conformation of collagen. Israel fournal of Chemistry 12:435-439.

Turpeenniemi-Hujanen M, Puistola U, Kivirikko KI 1980 Isolation of lysyl hydroxylase, an enzyme of collagen synthesis, from chick embryos as a homogeneous protein. Biochemistry fournal 189:247-253.

Young JS and BuRNS PE 1981 Pressure sores and the spinal cord injured. SCI Digest 3(3):9-17. Ibid, 1981 SCI Digest 3(4):11-23. 